\title{
Cell-free DNA as a potential biomarker in stroke: a comprehensive review of observational studies
}

\author{
Paul Thuan Tieu1, Michael H. Lee ${ }^{2}$, Tushar Dhawan ${ }^{3,5}$, Ha H. Nguyen ${ }^{4}$, Sajjad Afraz ${ }^{1}$, Jason Chung ${ }^{1,5}$, Shawn \\ Khan ${ }^{2}$, Ibrahim Yusuf ${ }^{5}$, Sophie Shu-Hsuan Liu ${ }^{5}$

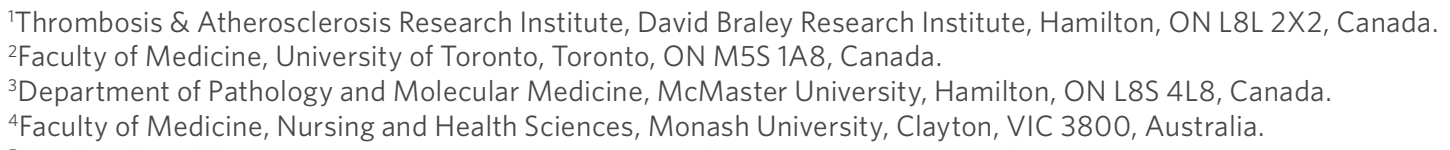

Correspondence to: Dr. Paul Thuan Tieu, Thrombosis \& Atherosclerosis Research Institute, David Braley Research Institute, 20 Copeland Ave, Hamilton, ON L8L 2X2, Canada. E-mail: tieut@mcmaster.ca

\begin{abstract}
How to cite this article: Tieu PT, Lee MH, Dhawan T, Nguyen HH, Afraz S, Chung J, Khan S, Yusuf I, Liu SSH. Cell-free DNA as a potential biomarker in stroke: a comprehensive review of observational studies. J Transl Genet Genom 2020;4:133-43. http://dx.doi.org/10.20517/jtgg.2020.18
\end{abstract}

Received: 24 Feb 2020 First Decision: 27 Mar 2020 Revised: 22 Apr 2020 Accepted: 26 May 2020 Published: 18 Jun 2020

Science Editor: Brian Chiu, Wei Zhang Copy Editor: Cai-Hong Wang Production Editor: Jing Yu

\begin{abstract}
Stroke is an abrupt loss of brain function, which is caused by the interruption of blood flow to the brain. Several blood biomarkers have been evaluated for the assessment of stroke severity and outcome. However, their roles remain limited in clinical practice. Circulating cell-free deoxyribonucleic acid (DNA) has emerged as a potential biomarker of stroke, as reported from several animal and human studies. In this study, we aim to review the prognostic values of cell-free DNA in stroke from all relevant cohort studies. The PubMed database was searched using keywords, "cell-free DNA" and "stroke" for relevant articles. Twelve studies ( $n=946$ patients) are included in the final analysis. While the prognostic values of cell-free DNA in predicting functional outcomes and hospital mortality after different types of stroke were highlighted in many studies, the inconsistency in methods hinders comparability between studies. Overall, the knowledge about the potential prognostic ability of cell-free DNA in stroke remains limited and conflicting. More robust studies with consistent methods are needed.
\end{abstract}

Keywords: Cell-free DNA, stroke, nucleosome, biomarker 


\section{INTRODUCTION}

Stroke is associated with significant morbidity and mortality and is noted to have a growing incidence worldwide, due to the increasing prevalence of cardiovascular associated diseases ${ }^{[1]}$. Cerebral ischemia is a detrimental neurological event where temporary or permanent depletion in blood flow causes injury in the brain $^{[2]}$. The consequent interaction of pathophysiological events such as inflammation, excitotoxicity, and apoptosis cause tissue damage that often results in a compromise of the blood-brain barrier ${ }^{[2]}$ and release of various neurobiological markers into circulation ${ }^{[3-5]}$. To date, various biomarkers have been discovered to support the diagnosis of stroke, however, none have acquired sufficient sensitivity or specificity to find a place in clinical practice ${ }^{[6]}$.

First reported in 1948 by Mandel and Metais, cell-free DNA (cfDNA) has become one of the centralized subjects for investigation in medical field research ${ }^{[7]}$. Cell-free DNA consists primarily of double-stranded nuclear DNA and mitochondrial DNA. Studies suggest that $90 \%$ of cfDNA is associated with exosomes ${ }^{[8]}$, where they are chromatinized and packaged into large extracellular vesicles ${ }^{[9]}$. Cell-free DNA circulates freely in blood plasma and is highly fragmented ${ }^{[7]}$. Thus, cfDNA can be collected during routine blood

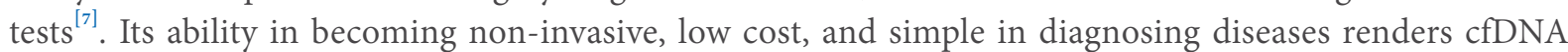
an idealistic biomarker ${ }^{[7]}$. Recent papers have suggested its usage within fields such as oncology, fetal prenatal and physical activity monitoring ${ }^{[7]}$, with several papers hinting at its potential in diagnosing and predicting prognosis in patients with stroke ${ }^{[10,11]}$. Despite the increase in the number of studies suggesting cfDNA's potential as a clinical biomarker, its origin, mechanism of release during a stroke, clearance, and physiological role remain widely unknown. The understanding of cfDNA origin and release mechanism can be advanced through studying cfDNA fragment size, which ranges from 150 bp to sizes larger than $10 \mathrm{kbp}^{[12,13]}$. Fragments of multiples of $150 \mathrm{bp}$ originate from apoptotic processes, specifically the endogenous cleavage of chromatin DNA into internucleosomal fragments. Larger fragments (>10 kbp) are believed to originate from necrotic processes ${ }^{[14]}$.

Previous studies ${ }^{[15]}$ have demonstrated approaches where analysis of blood cfDNA successfully differentiated ischemic stroke (IS) patients from stroke mimics. Successful candidates of diagnostic blood biomarkers of stroke should also be capable of efficiently differentiating between various stroke subtypes ${ }^{[5]}$. Although there have been various discoveries of biomarkers specific to subtypes of stroke, the role of cfDNA as a novel biomarker necessitates further exploration in its association with stroke subtypes. Such biomarkers could further be utilized diagnostically in non-invasively assessing stroke severity, which may vary between subtypes as well. Since the therapeutic window of stroke is narrow, occurring 3-6 h after onset of symptoms, the timely detection of severe patients and rapid implementation of the corresponding therapeutic measures have immense prognostic significance ${ }^{[16,17]}$. Furthermore, the clinical relevance of biomarkers could be crucial in predicting mortality or functional outcomes of patients, which necessitates further investigation of cfDNA in the context of stroke. Despite the elevation of blood cfDNA during various pathological events in the body ${ }^{[18]}$, conventionally, cfDNA has not gained importance as an ideal marker with specificity to a disease like stroke. Hence, this paper aims to examine the prognostic value of cfDNA in stroke through an examination of existing papers. The secondary objective is to explore the potential diagnostic values and to appraise the consistency in methods for measuring cfDNA.

\section{CRITERIA FOR CONSIDERING STUDIES FOR REVIEW}

The PubMed database was searched using keywords, "cell-free DNA" and "stroke" from inception to December, 2019. Inclusion criteria were limited to cohort or observational study on humans concerning cfDNA as a biomarker in stroke. Articles were excluded if they were non-human studies, comprised general reviews or editorials, and did not investigate cfDNA in the context of stroke. The references of the included articles were screened for further relevant studies. Data regarding: patient demographics, biological fluid 
collected, time of sampling, methods employed to measure DNA levels, clinical outcomes, and the values of cfDNA levels between case and control groups were extracted onto a spreadsheet (Excel v14, Microsoft).

\section{CURRENT RESEARCH STATUS}

Out of 165 articles initially retrieved, 6 articles were deemed to be relevant. The references of the included studies were further screened for relevant articles, and 6 more studies were additionally added. Overall, 12 studies ( $n=946$ patients), are included in the final analysis. Article characteristics are presented in Table 1. The prognostic/diagnostic values of blood cfDNA levels in stroke are presented in Table 2.

\section{Evidence for use of cfDNA in stroke recognition}

Several studies investigated the ability of cfDNA in recognizing stroke. Tsai et al. ${ }^{[19]}$ showed a significant elevation of plasma nuclear DNA and mitochondrial DNA in patients with acute IS $(n=50)$ compared to those in the control group $(n=50)$ who had no clinical evidence of stroke within one year. Blood samples were collected within 48 hours of stroke onset ${ }^{[19]}$. O'Connell et al ${ }^{[15]}$ reported similar elevation of peripheral blood cfDNA levels upon admission in patients suffering an acute IS $(n=43)$ relative to those diagnosed as stroke mimics $(n=20)$. These observations suggest that cfDNA may be diagnostically useful for the identification of IS during the acute phase of care. It is noteworthy in a study by Bustamante et al. ${ }^{[11]}$ that cfDNA levels upon admission trended higher in acute IS patients $(n=54)$ compared to healthy controls $(n=15)$, yet the result was not significant. Rainer et al. ${ }^{[20]}$ analyzed plasma DNA for the $\beta$-globin gene in a prospective studythat recruited patients presenting with stroke-like syndromes. Plasma $\beta$-globin DNA was significantly higher in patients suffering a hemorrhagic stroke $(n=118)$ than those without $(n=79)$, suggesting its ability to discriminate hemorrhagic from a non-hemorrhagic stroke ${ }^{[20]}$.

\section{Evidence for use of cfDNA in assessing stroke severity}

DNA is released into the serum as a cell death marker in a time and severity dependent manner after the onset of stroke. Therefore, the concentration of cfDNA can be clinically useful for assessing stroke severity. In a cohort of patients suffering acute IS, the levels of cfDNA in plasma collected within $72 \mathrm{~h}$ after onset in patients with National Institutes of Health Stroke Scale (NIHSS) score $>14$ were significantly higher than the mild group (Score: 0-1) or the moderate group (score: $2-14)^{[21]}$. Vajpeyee et al. ${ }^{[10]}$ assessed stroke severity by the NIHSS score in patients with IS. Plasma cfDNA correlated well with the severity of stroke at admission ${ }^{[10,22]}$. O'Connell et al. ${ }^{[15]}$ reported similar findings that plasma cfDNA levels were positively correlated with NIHSS and infarct volume in 43 patients experiencing an acute ischaemic stroke. In 88 patients with IS, intracerebral hemorrhage, or transient ischemic attacks, Rainer et al. ${ }^{[23]}$ found that cfDNA in plasma taken within 3 hours of symptom onset correlated well with the hemorrhagic volume, as measured by CT scan. In another study by Geiger et al. ${ }^{[24]}$, the levels of nucleosomal DNA on day 3 post-admission were also significantly correlated with infarct size in patients with cerebral IS ${ }^{[24]}$. These observations suggest that cfDNA levels can be useful for stratifying injury severity during triage.

\section{Evidence for use of cfDNA in predicting functional outcome}

Cell-free DNA has also been investigated for its ability to predict outcomes in patients suffering a stroke. In acute IS patients receiving tissue plasminogen activator, baseline cfDNA level cfDNA $<302.75$ kilogenomeequivalents/L (kg-equiv/L) was an independent predictor of neurological improvements at 48 hours, assessed by the NIHSS scale ${ }^{[11]}$. Geiger et al. ${ }^{[24]}$ assessed the functional outcome using the Barthel Index in 63 patients with cerebral IS. Nucleosome DNA was significantly higher in stroke patients with severe functional impairments than stroke patients with moderate to low functional impairment ${ }^{[24]}$. In two studies recruiting a total of 80 patients with IS, Vajpeyee et al. ${ }^{[22]}$ employed the modified Rankin scale (mRS) to determine the clinical outcome. They suggest the good utility of plasma cfDNA concentration upon admission as a predictor of a 3-month outcome in acute IS patients $(P=0.001)$ and neurological outcome after therapeutic interventions in the form of a mechanical thrombectomy or IV thrombolysis ${ }^{[10,22]}$. Lam et al. ${ }^{[25]}$ 


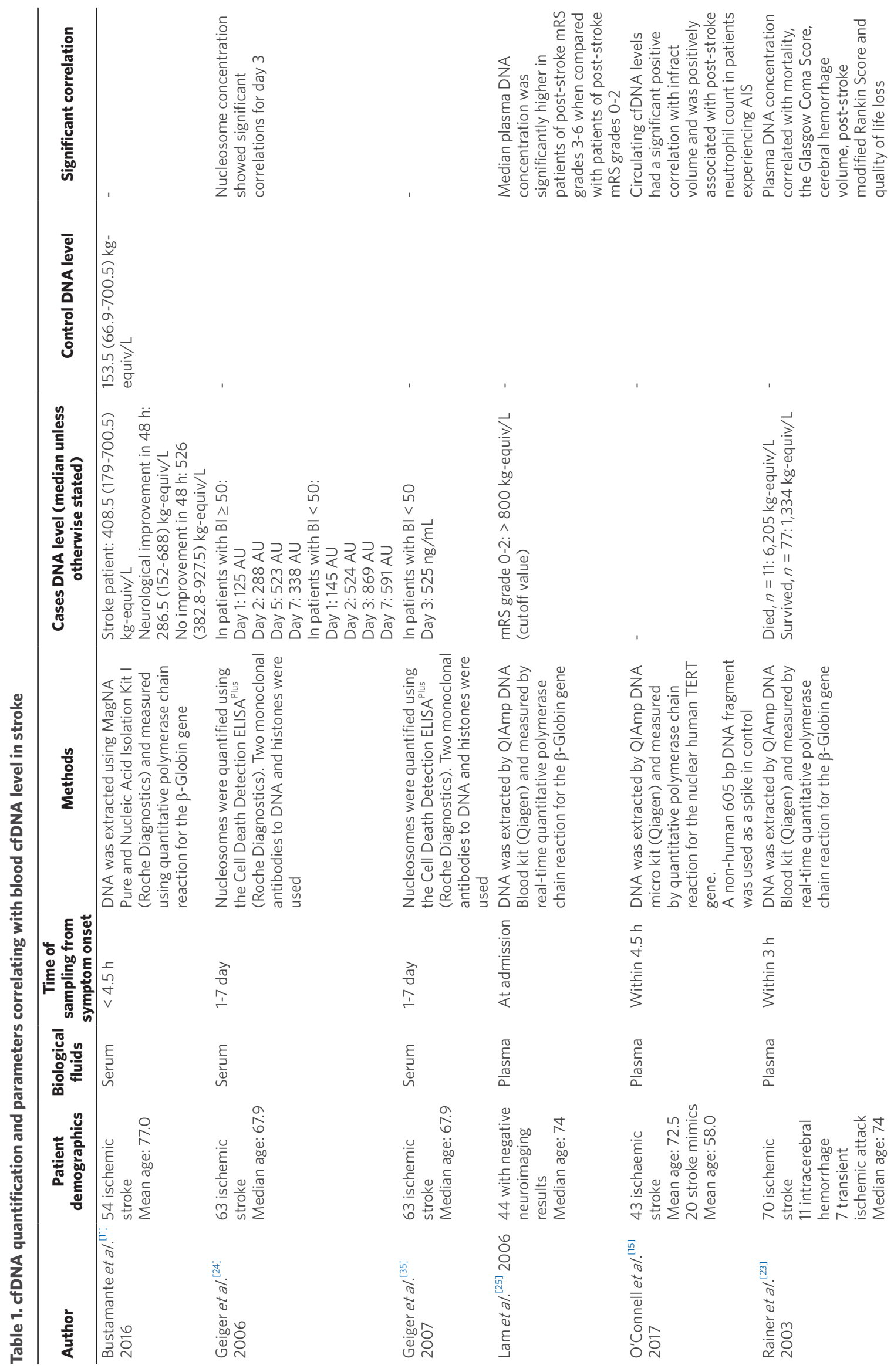




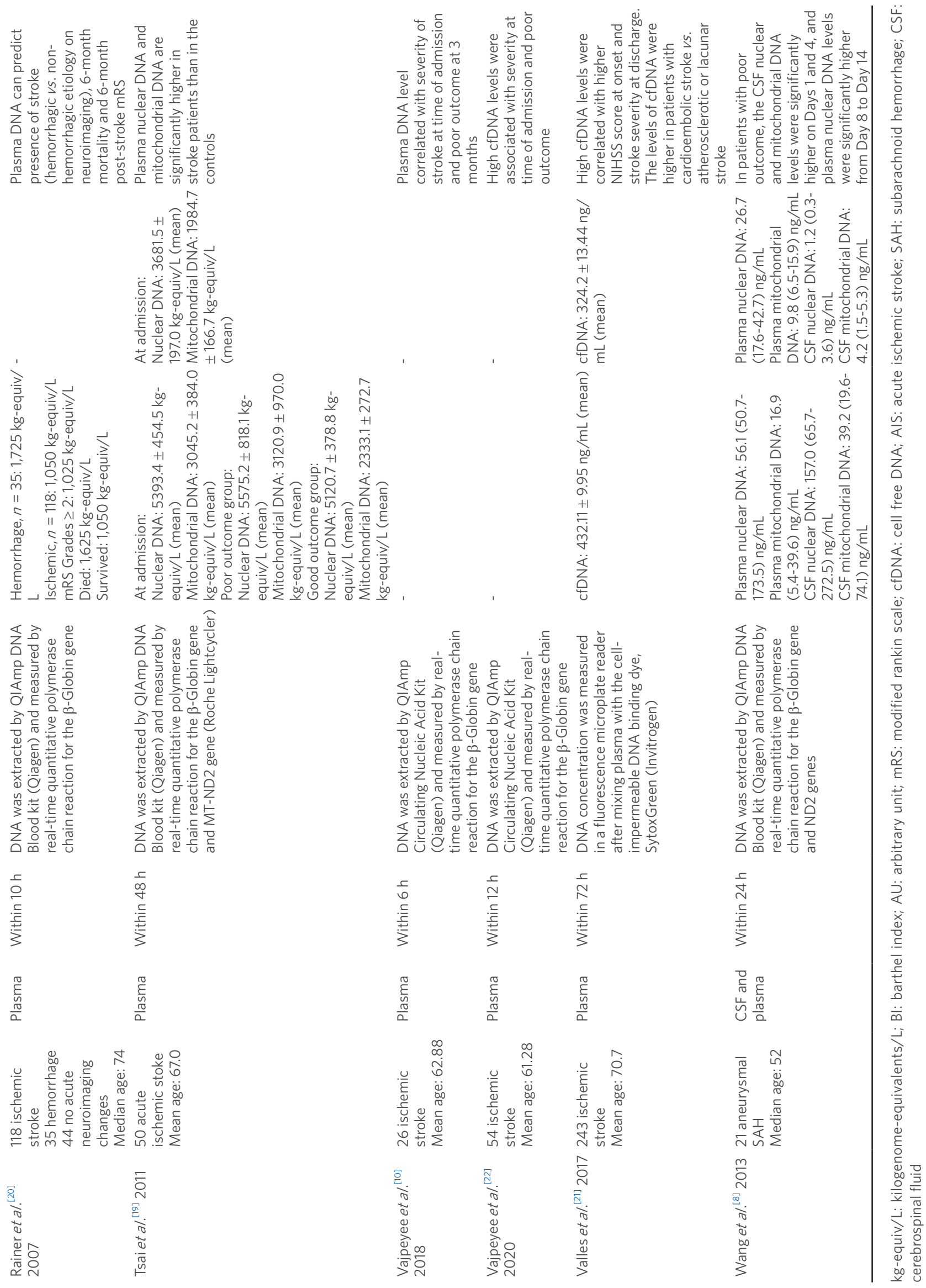


Table 2. Prognostic/diagnostic values of blood cfDNA levels in stroke

\begin{tabular}{|c|c|c|c|c|c|c|}
\hline Author & Outcome & $\begin{array}{c}\text { Marker and cutoff } \\
\text { value }\end{array}$ & $\begin{array}{l}\text { Sensitivity, \% } \\
(95 \% \mathrm{Cl})\end{array}$ & $\begin{array}{c}\text { Specificity, \% } \\
(95 \% \mathrm{Cl})\end{array}$ & $\begin{array}{c}\text { Area under ROC } \\
(95 \% \mathrm{Cl})\end{array}$ & Odds ratio \\
\hline $\begin{array}{l}\text { Bustamante et } a{ }^{\left[{ }^{[11]}\right.} \\
2016\end{array}$ & $\begin{array}{l}48 \text { h neurological } \\
\text { improvement }\end{array}$ & $\begin{array}{l}\text { cfDNA: }<302.75 \\
\text { kg-equiv/L }\end{array}$ & $\begin{array}{l}81(68.57- \\
89.37)\end{array}$ & $55(41.4-67.38)$ & - & $\begin{array}{l}\text { 43.8 (3.1-620.9) } \\
\text { (adjusted OR) }\end{array}$ \\
\hline $\begin{array}{l}\text { Geiger et } a{ }^{[35]} \\
2007\end{array}$ & $\begin{array}{l}\text { Non-recovery, } \mathrm{BI}< \\
100\end{array}$ & $\begin{array}{l}\text { Plasma } \\
\text { nucleosome } \\
\text { cfDNA on day } 3 \\
\text { after admission: } \\
560 \mathrm{ng} / \mathrm{mL}\end{array}$ & $\begin{array}{l}52.6(40.94- \\
65.12)\end{array}$ & $\begin{array}{l}100(94.31- \\
100)\end{array}$ & - & - \\
\hline Lam et al. ${ }^{[25]} 2006$ & $\begin{array}{l}\text { 6-month post-stroke } \\
\text { mRS, Grades 0-2 }\end{array}$ & $\begin{array}{l}\text { Plasma ncfDNA: > } \\
800 \text { kg-equiv/L }\end{array}$ & $\begin{array}{l}42(28.35- \\
56.75)\end{array}$ & $\begin{array}{l}100(91.96- \\
100)\end{array}$ & $\begin{array}{l}0.742(0.588- \\
0.862)\end{array}$ & - \\
\hline $\begin{array}{l}\text { Rainer et al. }{ }^{[23]} \\
2003\end{array}$ & Hospital mortality & $\begin{array}{l}\text { Plasma ncfDNA: > } \\
\text { 1,400 kg-equiv/L }\end{array}$ & $100(95.9-100)$ & $\begin{array}{l}74.4(64.63- \\
82.66)\end{array}$ & $\begin{array}{l}0.89(0.80- \\
0.94)\end{array}$ & $\begin{array}{l}\text { Mortality: } 1.6(1.1-2.4 ; \\
P=0.03) \\
\text { 6-month post-Rankin } \\
\text { Score }>2: 1.8(1.0- \\
3.3 ; P=0.05)\end{array}$ \\
\hline $\begin{array}{l}\text { Rainer et } a{ }^{\left[{ }^{[20]}\right.} \\
2007\end{array}$ & $\begin{array}{l}\text { Stroke type: } \\
\text { hemorrhagic stroke } \\
\text { vs. (ischemic stroke } \\
\text { and patients without } \\
\text { acute neuroimaging } \\
\text { changes) }\end{array}$ & $\begin{array}{l}\text { Plasma ncfDNA: > } \\
\text { 2,500 kg-equiv/L }\end{array}$ & $\begin{array}{l}31(25.06- \\
37.93)\end{array}$ & $\begin{array}{l}83(77.29- \\
87.74)\end{array}$ & - & $\begin{array}{l}4.24(1.88-9.56 ; P= \\
0.0011)\end{array}$ \\
\hline $\begin{array}{l}\text { Vajpeyee et al. }{ }^{[10]} \\
2018\end{array}$ & $\begin{array}{l}\text { Better outcome at } 3 \\
\text { months for patients } \\
\text { who underwent IVT } \\
\text { and/or mechanical } \\
\text { thrombectomy }\end{array}$ & $\begin{array}{l}\operatorname{cfDNA}:<10,000 \\
\text { kg-equiv/L }\end{array}$ & 78 & 83 & $\begin{array}{l}0.79(0.67- \\
0.92 ; P=0.02)\end{array}$ & $\begin{array}{l}40.33(1.50-293.25 \\
P=0.000)\end{array}$ \\
\hline \multirow[t]{2}{*}{ Wang et al. ${ }^{[8]} 2013$} & $\begin{array}{l}\text { 6-month post-stroke } \\
\text { mRS, score } \geq 3\end{array}$ & $\begin{array}{l}\text { CSF ncfDNA: } 85.1 \\
\mathrm{ng} / \mathrm{mL}\end{array}$ & 89 & 75 & - & - \\
\hline & & $\begin{array}{l}\text { CSF mcfDNA: } 31.4 \\
\mathrm{ng} / \mathrm{mL}\end{array}$ & 89 & 100 & & \\
\hline
\end{tabular}

cfDNA: cell free DNA; kg-equiv/L: kilogenome-equivalents/L; BI: barthel index; ncfDNA: nuclear cell free DNA; IVT: intravenous thrombolysis; mRS: modified rankin scale; CSF: cerebrospinal fluid; mcfDNA: mitochondrial cell free DNA

also evaluated the 6-month outcome of their patients with the mRS scale. In patients with negative neuroimaging results, there was a significant difference in plasma DNA levels at admission between the good outcome (mRS 0-2) group and the poor outcome (mRS 3-6) group $^{[25]}$. On the other hand, Wang et al. ${ }^{[26]}$ found that in patients with acute spontaneous aneurysmal subarachnoid hemorrhage stroke, higher levels of cfDNA in plasma and nuclear and mitochondrial DNA in CSF upon admission are associated with the worse 6-month clinical outcome on the mRS scale. Overall, these findings suggested cfDNA as a good prognostic marker for stroke.

\section{Evidence for use of cfDNA in predicting mortality}

One of the main patient-important outcomes which have been examined in existing studies is mortality. In one of the preliminary studies describing the relationship between cfDNA and patient-important outcomes, Rainer et al. ${ }^{[23]}$ described a $100 \%$ sensitivity and $74.4 \%$ specificity in using cfDNA as a prognostic biomarker for both ischaemic and hemorrhagic stroke ${ }^{[5]}$. Under categorical analysis, a cfDNA level of $>$ $1,400 \mathrm{~kg}$-equiv/L indicated a significant $60 \%$ increase of odds risk for the event of mortality at 6-months. Furthermore, in an updated study by the same group in 2007, a significant difference between cfDNA at $48 \mathrm{~h}$ post-stroke was as strong a predictor of 6-month mortality, with a 50\% lower cfDNA levels for those without an event ${ }^{[20]}$.

\section{CURRENT APPLICATION OF CELL-FREE DNA IN STROKE}

In this review, we summarize evidence that pertains to the biomarker prognostic value of cfDNA and stroke outcomes. Patient-important outcomes have been explored such as neurological outcomes (as assessed by $\mathrm{mRS}$ ), infarction volume, and stroke severity at discharge. All of these factors were strongly 
statistically significant in all the reported studies and demonstrated a high level of correlation. With a total of 484 patients from 7 studies ${ }^{[10,11,20,22,23,25,26]}$, the evidence is quite compelling for cfDNA's predictive value of at-discharge and 3-month post-event mRS scale. With this in mind, it would be of benefit to consider the cfDNA as a simple test to adequately administer a more intensive post-discharge monitoring to stroke patients with poorer prognosis. Therefore, cell-free DNA has been proposed as another objective predictor of outcomes post-stroke. It can be analogously compared to troponin levels in myocardial infarction. The mechanism by which cell-free DNA increases in the plasma of patients suffering a stroke is still being studied. The stroke resulted from a complex cascade of events including cerebral ischemia, altered cerebral blood flow, inflammation, the production of reactive oxygen radicals, neuronal necrosis, and apoptosis ${ }^{[27-29]}$. Free DNA can be released from apoptotic cells, as observed in cancer ${ }^{[30,31]}$ and trauma ${ }^{[32]}$. On the other hand, there is a possibility that other non-cerebral tissue pathologies associated with cell death may contribute to the increased cfDNA content in the plasma after stroke.

It is important to note that the majority of the studies report on ischaemic stroke. Out of the 12 articles, 10 articles $(n=781)$ reported on ischaemic stroke, whereas only 2 articles $(n=46)$ reported on hemorrhagic strokes - with one of the two studies being a mixed population with IS. Amongst the evidence for ischaemic strokes, 8 found a significant correlation between cfDNA and outcomes, such as those mentioned above. For the two articles examining hemorrhagic stroke, the correlations with cfDNA were significant; however, only one study performed a sensitivity analysis on their results and demonstrated that differences in cfDNA due to differing aetiologies. This suggests that although there is significant evidence for the correlation of cfDNA with ischaemic stroke, there remains a lack of data for both the correlation between hemorrhagic stroke and cfDNA. Furthermore, the prognostic potential of mitochondrial cfDNA was evaluated in only two studies, recruiting patients suffering from acute IS and subarachnoid hemorrhage ${ }^{[19,26]}$. Mitochondrial cfDNA is associated with the systemic and local immune responses, which have important roles in causing stroke as well as the progression of ischemic lesions ${ }^{[33,34]}$. However, the lack of data currently does not allow us to conclude mitochondrial cfDNA as a useful biomarker in stroke.

The benefit and clinical usefulness of cfDNA in predicting functional outcomes and long-term survival are apparent. The strength of using plasma cfDNA as a prognostic marker is that it is non-invasive and simple. It has also been demonstrated to be able to discriminate hemorrhagic from non-hemorrhagic stroke as well as being an independent predictor of the result of stroke in patients with negative neuroimaging ${ }^{[20,25]}$. Cell-free DNA can assist clinicians in patient examination and complement imaging tools to enhance the accuracy of stroke diagnosis. In addition, it can augment the diagnostic workup and help triage patients for intervention. In cases where imaging is negative or not indicated, cfDNA prognostic utility can assist the patients and clinicians in making informed decisions regarding invasive or medical treatment.

Despite the proven ability of cfDNA in predicting the prognosis of patients within the discharge and postdischarge setting, there remains conflicting evidence on its predictive value within the discharge setting. The notion remains true as studies conducted by Bustamante et al. ${ }^{[11]}$ and O'connell et al. ${ }^{[15]}$ indicated a weak correlation between cfDNA and NIHSS score. In contrast, these findings were not replicated in studies presented by Vajpeyee et al. ${ }^{[10]} 2018$, Vajpeyee et al ${ }^{[22]} 2020$, and Valles et al. ${ }^{[21]} 2017$ as they have indicated a strong correlation between cfDNA and NIHSS. Thus, due to conflicting evidence presented in current studies, it remains unclear the predictive value of cfDNA and its correlation to NIHSS onstroke severity. However, differences in findings may be attributable to differences in baseline patient demographics used by these studies. Additionally, the lack of separation of ischaemic stroke and hemorrhagic stroke, regarding its correlation to NIHSS during an assessment may also contribute to the heterogeneity in findings. Other factors that may contribute to the conflicting outcomes also include the lack of analyses of factors such as sex and infarct volume. These factors are significant predictors of prognosis during post-event. Notably, differences in findings may be corrected if these factors are addressed in future studies, potentially leading to the production of stronger and more robust findings. 


\section{Methodological Considerations for Quantifying cfDNA}

In some studies ${ }^{[11,24,35]}$, cfDNA was measured in serum, while in others ${ }^{[10,15,19-23,25,26]}$ it was measured in the blood plasma. It has been known that cfDNA is more abundant in serum than in plasma samples and there is a large variation of cfDNA in serum between patients. A major fraction of cfDNA in the blood serum might be formed during the coagulation cascade, which leads to the lysis of white blood cells ${ }^{[36,37]}$. Therefore, this effect can introduce errors to the obtained results. Geiger et al. ${ }^{[35]}$ measured cfDNA in the serum of patients suffering an IS and found no statistically significant differences in the cfDNA levels between the severe and mild cases in the first day of the stroke, which was in contrast to the findings of other authors ${ }^{[24]}$. In addition, Wang et al. ${ }^{[26]}$ measured the content of cfDNA in the cerebrospinal fluid (CSF) of patients suffering a subarachnoid hemorrhage. Interestingly, the cfDNA concentrations in the CSF, not in plasma, on admission were significantly increased in patients with worse outcomes. The observed differences in CfDNA level between plasma and CSF at the same timepoint can be explained by the different sources of cfDNA in these fluids and the differences in the dynamics of the blood-brain barrier and CSFbrain barrier integrity changes during a stroke ${ }^{[3,39]}$. Overall, the results between different sample types, such as a serum, plasma, or CSF, shouldn't be compared with one another ${ }^{[40]}$.

Furthermore, inconsistencies in the sampling time severely limit the applicability and coalescing of evidence. The notion can predominantly be seen across all 12 studies, as there remains a lack of standardized sampling time protocol. The sampling time ranges significantly between zero (on admission) up to $72 \mathrm{~h}$ within the onset of symptoms. Sampling frequency also ranges from once to daily as long as the patient is admitted. Knowing that cfDNA is a transient molecule, it may be beneficial to standardize the collection time to ensure that cfDNA is captured within the time frame of rising, peak or falling levels. The timing of diagnosis is crucial since the therapeutic window for stroke is narrow after the onset of symptoms ${ }^{[16,17]}$.

Another factor that limits the accuracy of biomarker interpretation is the use of different methods in extracting and measuring cfDNA. The majority of studies included in our analysis employed the QIAamp circulating nucleic acid kit for DNA extraction. The QIA kit has been reported to be highly efficient and produces high cfDNA yields ${ }^{[41-43]}$. While the ultimate goal was to quantify cell death, there were different protocols used across studies including the use of quantitative PCR, cell death detection enzyme-linked immunosorbent assay, and a nucleic acid immunofluorescent counterstain. The current cfDNA assay protocol in stroke is not standardized and there has been little investigation of consistency regarding the quantitative PCR methods used for cfDNA quantification. The widely-used technique to determine cfDNA concentration is quantitative $\mathrm{PCR}^{[10,11,19,20,22,23,25,26]}$. During the quantitative PCR process, the total DNA isolated from plasma or serum is eluted in a fixed volume of buffer. Then, qPCR targeting 1 or more loci, such as the $\beta$-globin gene for nuclear cfDNA and of the MT-ND2 gene for mitochondrial cfDNA, is performed using a fixed volume of eluent as input. The concentration of cfDNA in the sample is determined from the detection of these loci. This process is based on an assumption that DNA extraction efficiencies are similar between specimens. However, O'Connell et al.$^{[4]}$ demonstrated a large variation in extraction efficiencies between specimens, with a coefficient of variance of $28.9 \%$. This effect can cause significant artificial variance with regards to downstream cfDNA quantification. To control for this potential confounder, an exogenous spike-in oligonucleotide fragment has been employed to normalize cfDNA levels ${ }^{[15]}$. Similar strategies using exogenous spike-in control to account for variance are often used in miRNA quantification, but the technique has yet to be adopted for quantification of $\mathrm{cfDNA}^{[45]}$. Other techniques include extracting DNA by nuclear monoclonal antibodies and the cfDNA content was measured using commercial ELISA kit ${ }^{[24,35]}$. A more effective approach using the integrity index has been introduced in studies investigating oncology patients ${ }^{[46,47]}$.

The lack of standardization and appropriate controls hinders the use of cfDNA as a biomarker for stroke diagnosis and monitoring. Results between studies are not comparable due to differences in sample 
processing methods, storage conditions, and techniques for both the extraction and quantification. This can lead to errors in determining cut-off points and assay sensitivity and specificity. Therefore, accurate and standardized quantification of cfDNA will aid the future clinical implementation of this approach. For instance, the use of an exogenous spike-in control is a step towards the right direction to limit artificial variance induced during DNA extraction. There are other potential confounders during blood collection, processing, and storage that causes DNA degradation and leukocyte enucleation. Different approaches to cfDNA extraction, storage, and assay have been described along with their benefits and disadvantages in detail by Wong et al. ${ }^{[48]}$, El Messaoudi et al. ${ }^{[49]}$, and Malentacchi et al ${ }^{[50]}$. Efforts have been made to limit these variances, including the use of specifically designed blood preservatives for cfDNA analysis and the institutional specimen handling protocols for clinical blood collection ${ }^{[48,51]}$. It is perhaps beneficial in adhering to a standardized protocol to bolster the robustness of the current cfDNA in biomarker prognosis. Due to the inconsistency of biomarker collection and processing, conclusions and significance in results may be inherently limited.

\section{CONCLUSION}

The prognostic values of cell-free DNA in predicting functional outcomes and hospital mortality have been demonstrated in a limited number of studies. The inconsistency in the DNA extraction and quantification method hinders comparability between studies. This prompts future trials to conduct more robust cohort studies that may describe the most optimal collection times for stroke prediction as well as cfDNA processing that yields the most accurate prediction.

\section{DECLARATIONS}

\section{Authors' contributions}

Took part in the design of this paper: Tieu PT, Lee MH, Dhawan T, Nguyen HH, Afraz S, Chung J, Khan S, Yusuf I, Liu SSH

Performed the literature search, data extraction, and analysis: Tieu PT

Drafted the manuscript: Lee MH, Dhawan T, Nguyen HH, Afraz S, Chung J, Khan S

Provided material support and prepared the tables: Yusuf I, Liu SSH

\section{Availability of data and materials}

Not applicable.

\section{Financial support and sponsorship}

None.

\section{Conflicts of interest}

All authors declared that there are no conflicts of interest.

\section{Ethical approval and consent to participate}

Not applicable.

\section{Consent for publication}

Not applicable.

\section{Copyright}

(c) The Author(s) 2020. 


\section{REFERENCES}

1. Donkor ES. Stroke in the 21(st) century: a snapshot of the burden, epidemiology, and quality of life. Stroke Res Treat 2018;2018:3238165.

2. Dirnagl U, Iadecola C, Moskowitz MA. Pathobiology of ischaemic stroke: an integrated view. Trends Neurosci 1999;22:391-7.

3. Jickling GC, Sharp FR. Blood biomarkers of ischemic stroke. Neurotherapeutics 2011;8:349-60.

4. Hasan N, McColgan P, Bentley P, Edwards RJ, Sharma P. Towards the identification of blood biomarkers for acute stroke in humans: a comprehensive systematic review. Br J Clin Pharmacol 2012;74:230-40.

5. Miao Y, Liao JK. Potential serum biomarkers in the pathophysiological processes of stroke. Expert Rev Neurother 2014;14:173-85.

6. Saenger AK, Christenson RH. Stroke biomarkers: progress and challenges for diagnosis, prognosis, differentiation, and treatment. Clin Chem 2010;56:21-33.

7. Ranucci R. Cell-free DNA: applications in different diseases. Methods Mol Biol 2019;1909:3-12.

8. Wang W, Kong P, Ma G, Li L, Zhu J, et al. Characterization of the release and biological significance of cell-free DNA from breast cancer cell lines. Oncotarget 2017;8:43180-91.

9. Kustanovich A, Schwartz R, Peretz T, Grinshpun A. Life and death of circulating cell-free DNA. Cancer Biol Ther 2019;20:1057-67.

10. Vajpeyee A, Wijatmiko T, Vajpeyee M, Taywade O. Cell free DNA: a novel predictor of neurological outcome after intravenous thrombolysis and/or mechanical thrombectomy in acute ischemic stroke patients. Neurointervention 2018;13:13-9.

11. Bustamante A, Mancha F, Macher HC, Garcia-Berrocoso T, Giralt D, et al. Circulating cell-free DNA is a predictor of short-term neurological outcome in stroke patients treated with intravenous thrombolysis. J Circ Biomark 2016;5:1849454416668791.

12. Bronkhorst AJ, Wentzel JF, Aucamp J, van Dyk E, du Plessis L, et al. Characterization of the cell-free DNA released by cultured cancer cells. Biochim Biophys Acta 2016;1863:157-65.

13. Jahr S, Hentze H, Englisch S, Hardt D, Fackelmayer FO, et al. DNA fragments in the blood plasma of cancer patients: quantitations and evidence for their origin from apoptotic and necrotic cells. Cancer Res 2001;61:1659-65.

14. Zhivotosky B, Orrenius S. Assessment of apoptosis and necrosis by DNA fragmentation and morphological criteria. Curr Protoc Cell Biol 2001; 18:18.3.1-23.

15. O'Connell GC, Petrone AB, Tennant CS, Lucke-Wold N, Kabbani Y, et al. Circulating extracellular DNA levels are acutely elevated in ischaemic stroke and associated with innate immune system activation. Brain Inj 2017;31:1369-75.

16. Sandercock P, Wardlaw JM, Lindley RI, Dennis M, Cohen G, et al. The benefits and harms of intravenous thrombolysis with recombinant tissue plasminogen activator within $6 \mathrm{~h}$ of acute ischaemic stroke (the third international stroke trial [IST-3]): a randomised controlled trial. Lancet 2012;379:2352-63.

17. Hanselman CJ. Timing of tissue plasminogen activator for acute ischemic stroke: outcomes-based recommendations for practice. J Neurosci Nurs 2014;46:314-20.

18. Swarup V, Rajeswari MR. Circulating (cell-free) nucleic acids--a promising, non-invasive tool for early detection of several human diseases. FEBS Lett 2007;581:795-9.

19. Tsai NW, Lin TK, Chen SD, Chang WN, Wang HC, et al. The value of serial plasma nuclear and mitochondrial DNA levels in patients with acute ischemic stroke. Clin Chim Acta 2011;412:476-9.

20. Rainer TH, Wong KS, Lam W, Lam NY, Graham CA, et al. Comparison of plasma beta-globin DNA and S-100 protein concentrations in acute stroke. Clin Chim Acta 2007;376:190-6.

21. Valles J, Lago A, Santos MT, Latorre AM, Tembl JI, et al. Neutrophil extracellular traps are increased in patients with acute ischemic stroke: prognostic significance. Thromb Haemost 2017;117:1919-29.

22. Vajpeyee A, Wijatmiko T, Vajpeyee M, Taywade O, Pandey S, et al. Clinical usefulness of cell-free DNA as a prognostic marker in acute ischemic stroke. Neurologist 2020;25:11-3.

23. Rainer TH, Wong LK, Lam W, Yuen E, Lam NY, et al. Prognostic use of circulating plasma nucleic acid concentrations in patients with acute stroke. Clin Chem 2003;49:562-9.

24. Geiger S, Holdenrieder S, Stieber P, Hamann GF, Bruening R, et al. Nucleosomes in serum of patients with early cerebral stroke. Cerebrovasc Dis 2006;21:32-7.

25. Lam NY, Rainer TH, Wong LK, Lam W, Lo YM. Plasma DNA as a prognostic marker for stroke patients with negative neuroimaging within the first $24 \mathrm{~h}$ of symptom onset. Resuscitation 2006;68:71-8.

26. Wang HC, Yang TM, Lin WC, Lin YJ, Tsai NW, et al. The value of serial plasma and cerebrospinal fluid nuclear and mitochondrial deoxyribonucleic acid levels in aneurysmal subarachnoid hemorrhage. J Neurosurg 2013;118:13-9.

27. Sairanen T, Carpen O, Karjalainen-Lindsberg ML, Paetau A, Turpeinen U, et al. Evolution of cerebral tumor necrosis factor-alpha production during human ischemic stroke. Stroke 2001;32:1750-8.

28. Graham SH, Chen J. Programmed cell death in cerebral ischemia. J Cereb Blood Flow Metab 2001;21:99-109.

29. Reed JC. Mechanisms of apoptosis. Am J Pathol 2000;157:1415-30.

30. Stroun M, Anker P, Maurice P, Lyautey J, Lederrey C, et al. Neoplastic characteristics of the DNA found in the plasma of cancer patients. Oncology 1989;46:318-22.

31. Fournie GJ, Courtin JP, Laval F, Chale JJ, Pourrat JP, et al. Plasma DNA as a marker of cancerous cell death. Investigations in patients suffering from lung cancer and in nude mice bearing human tumours. Cancer Lett 1995;91:221-7.

32. Lo YM, Rainer TH, Chan LY, Hjelm NM, Cocks RA. Plasma DNA as a prognostic marker in trauma patients. Clin Chem 2000;46:319-23.

33. Itagaki K, Kaczmarek E, Lee YT, Tang IT, Isal B, et al. Mitochondrial DNA released by trauma induces neutrophil extracellular traps. PLoS One 2015;10:e0120549.

34. Dziedzic T. Systemic inflammation as a therapeutic target in acute ischemic stroke. Expert Rev Neurother 2015;15:523-31. 
35. Geiger S, Holdenrieder S, Stieber P, Hamann GF, Bruening R, et al. Nucleosomes as a new prognostic marker in early cerebral stroke. J Neurol 2007;254:617-23.

36. Holdenrieder S, Stieber P, Chan LY, Geiger S, Kremer A, et al. Cell-free DNA in serum and plasma: comparison of ELISA and quantitative PCR. Clin Chem 2005;51:1544-6.

37. Lee TH, Montalvo L, Chrebtow V, Busch MP. Quantitation of genomic DNA in plasma and serum samples: higher concentrations of genomic DNA found in serum than in plasma. Transfusion 2001;41:276-82.

38. Xiang J, Routhe LJ, Wilkinson DA, Hua Y, Moos T, et al. The choroid plexus as a site of damage in hemorrhagic and ischemic stroke and its role in responding to injury. Fluids Barriers CNS 2017;14:8.

39. Serrone JC, Maekawa H, Tjahjadi M, Hernesniemi J. Aneurysmal subarachnoid hemorrhage: pathobiology, current treatment and future directions. Expert Rev Neurother 2015;15:367-80

40. Bronkhorst AJ, Aucamp J, Pretorius PJ. Cell-free DNA: preanalytical variables. Clin Chim Acta 2015;450:243-53.

41. Sorber L, Zwaenepoel K, Deschoolmeester V, Roeyen G, Lardon F, et al. A comparison of cell-free DNA isolation kits: isolation and quantification of cell-free DNA in plasma. J Mol Diagn 2017;19:162-8.

42. Devonshire AS, Whale AS, Gutteridge A, Jones G, Cowen S, et al. Towards standardisation of cell-free DNA measurement in plasma: controls for extraction efficiency, fragment size bias and quantification. Anal Bioanal Chem 2014;406:6499-512.

43. Page K, Guttery DS, Zahra N, Primrose L, Elshaw SR, et al. Influence of plasma processing on recovery and analysis of circulating nucleic acids. PLoS One 2013;8:e77963.

44. O'Connell GC, Chantler PD, Barr TL. High interspecimen variability in nucleic acid extraction efficiency necessitates the use of spike-in control for accurate qPCR-based measurement of plasma cell-free DNA levels. Lab Med 2017;48:332-8.

45. Kroh EM, Parkin RK, Mitchell PS, Tewari M. Analysis of circulating microRNA biomarkers in plasma and serum using quantitative reverse transcription-PCR (qRT-PCR). Methods 2010;50:298-301.

46. Yu J, Gu G, Ju S. Recent advances in clinical applications of circulating cell-free DNA integrity. Lab Med 2014;45:6-11.

47. Huang A, Zhang X, Zhou SL, Cao Y, Huang XW, et al. Plasma circulating cell-free DNA integrity as a promising biomarker for diagnosis and surveillance in patients with hepatocellular carcinoma. J Cancer 2016;7:1798-803.

48. Wong D, Moturi S, Angkachatchai V, Mueller R, DeSantis G, et al. Optimizing blood collection, transport and storage conditions for cell free DNA increases access to prenatal testing. Clin Biochem 2013;46:1099-104.

49. El Messaoudi S, Rolet F, Mouliere F, Thierry AR. Circulating cell free DNA: preanalytical considerations. Clin Chim Acta 2013;424:222-30.

50. Malentacchi F, Pizzamiglio S, Verderio P, Pazzagli M, Orlando C, et al. Influence of storage conditions and extraction methods on the quantity and quality of circulating cell-free DNA (ccfDNA): the SPIDIA-DNAplas external quality assessment experience. Clin Chem Lab Med 2015;53:1935-42.

51. Toro PV, Erlanger B, Beaver JA, Cochran RL, VanDenBerg DA, et al. Comparison of cell stabilizing blood collection tubes for circulating plasma tumor DNA. Clin Biochem 2015;48:993-8. 